\title{
PENINGKATAN KUALITAS UKM SENI PAHAT MELALUI INOVASI PRODUK DAN PENGGUNAAN PENGAWET KAYU ALAMI
}

\author{
Siswi Astuti ${ }^{1)}$, F. Endah Kusuma $\mathbf{R}^{2)}$, Tjitjik Sriwardhani ${ }^{3)}$ \\ ${ }^{1,2)}$ Fakultas Teknologi Industri, Institut Teknologi Nasional Malang \\ ${ }^{3)}$ Fakultas Ilmu Pendidikan, Universitas Negeri Malang \\ E-Mail :endahkr@lecturer.itn.ac.id
}

\begin{abstract}
Abstrak
Masyarakat Bakalankrajan khususnya warga RW 02 merupakan masyarakat yang sangat kreatif hal ini ditunjukkan dengan adanya produk unggulan pada masing-masing RT. UKM seni pahat berdomisili di RT 07 mempunyai keunggulan seni pahat kayu, dimana cara memahat dengan memakai parang sehingga produk pahatan kurang halus serta kurang inovatif. Hal ini berdampak pada tingkat pemesanan yang menurun dan akhirnya tidak berjualan lagi. Program dari RW 02 tahun 2018 adalah meningkatkan kesejahteraan warga dengan cara menghidupkan lagi kemampuan warganya sesuai dengan keahlian masing-masing. Program ini tidak dapat berjalan dengan lancar karena membutuhkan dana untuk pembelian peralatan dan juga membutuhkan pelatih yang sesuai dengan bidangnya. Hasil evaluasi sementara seni pahat dan ukir jika dipahami dan ditekuni dengan baik oleh UKM dapat meningkatkan perekonomiannya karena pada dasarnya UKM tersebut mempunyai kesenangan dalam hal seni pahat. Untuk itu disusunlah suatu kegiatan pelatihan seni pahat. Pelatihan seni pahat dilaksanakan selama 7 bulan dimana materi pelatihannya meliputi pembuatan desain seni pahat dan ukir, pembuatan pengawet kayu yang berupa insektisida dari bahan alami, cara penggunaan insektisida alami, praktek pembuatan produk seni pahat dan ukir, pengeringan bahan dasar memakai mesin pengering serta materi tentang komposisi warna. Setelah praktek pembuatan produk selesai maka selanjutnya untuk menentukan harga jual diberikan materi tentang analisa ekonomi, dan cara memasarkan melalui media elektronik. Hasil dari pelatihan ini produk yang sudah terjual sebanyak 4 (empat) produk kepala naga sedangkan yang masih dikerjakan pesanan pembuatan cermin ukiran kayu dan permintaan perbaikan pahatan yang sudah using untuk dimodifikasi lagi menjadi bentuk baru. Media elektronik yang sudah dibuat adalah @bakra kreatif singkatan dari Bakalankrajan kreatif. Produk Kepala Naga yang belum diwarnai dijual dengan harga Rp 600.000,00 sedangkan yang sudah diwarnai seharga Rp 900.000,00. Untuk penambahan hiasan pada kepala naga, dijual dengan harga Rp 300.000,00. Pendampingan ini akan dilaksanakan terus sampai terwujud visi RW 02 yaitu Kampung Wisata Kreatif Bakalankrajan.
\end{abstract}

Kata kunci : seni pahat, insektisida alami, produktivitas

\section{PENDAHULUAN}

RW 02 Bakalankrajan merupakan salah satu rukun warga yang berada pada wilayah situs sejarah kelurahan Bakalankrajan yang diduga merupakan desa kuno. Hal ini dapat dibuktikan dengan sering ditemukannya benda cagar budaya RW 02 Bakalankrajan beralamat di jalan Pelabuhan Tanjung Perak memiliki luas wilayah sekitar 9,00 Ha, memiliki penduduk berjumlah 951 jiwa dengan jumlah pendidikan terbesar adalah SMA sebanyak 257 orang sedangkan mata pencaharian terbanyak sebagai buruh 792 orang. RW 02 terdiri dari 5 RT dengan berbagai macam keahlian yaitu pembuatan produk layang-layang, tali kor, karang kitri, kuda lumping, daur ulang limbah kertas, ternak burung hias, kesenian keroncong. RT 07 mempunyai jumlah penduduk terbanyak yaitu 215 orang dengan tingkat pendidikan TK 15 orang, SD 33 orang, SMP 36 orang, SMA 49 orang dan Perguruan Tinggi 13 orang. Jenis pekerjaan terbanyak sebagai buruh bangunan dan buruh pabrik rokok sebanyak 180 orang, hanya sedikit yang berwirausaha yaitu 6 orang dan PNS 4 orang. Rendahnya jumlah warga yang mempunyai tingkat pendidikan tinggi berdampak pada perekonomian warga, mereka cenderung untuk bertahan hidup dengan pekerjaan seadanya padahal sebetulnya masyarakat RT 07 mempunyai banyak ide cemerlang yang dapat meningkatkan perekonomian mereka. Hal ini dapat dilihat dari adanya kegiatan pameran produk yang sering dilakukan pada momen-momen tertentu contohnya pada saat peresmian ketua RW 02, ulang tahun Kota Malang, ulang tahun RI. Ide yang ditampilkan bagus tetapi karena peralatan dan 
keahlian yang kurang mendukung berdampak pada kualitas produk yang dihasilkan sehingga apabila dijual kurang laku.

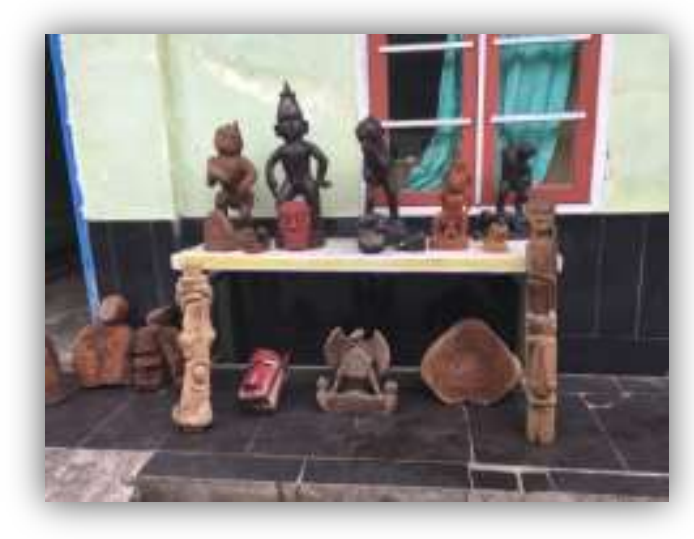

Gambar 1. Produk seni ukir/pahat

Permasalahan yang dihadapi oleh masyarakat RT 07 RW 02 Bakalan Krajan adalah rendahnya tingkat pendidikan, rendahnya ketrampilan yang dimiliki, kurangnya dana untuk mewujudkan minat dan kreatifitas mereka mengakibatkan tidak dapatnya mengembangkan usaha kreatif yang mereka inginkan. Seni pahat dan ukir yang menjadi unggulan usaha masyarakat RT 07 sekarang menjadi tidak ada karena tidak adanya minat masyarakat yang memesannya. Hal ini karena desain dari seni pahatnya yang kurang menarik dan monoton serta produk kurang bermanfaat, pengerjaannya masih kasar dengan memakai peralatan parang saja, serta tidak ada variasi warna sehingga lebih menarik.

Tujuan dari kegiatan pengabdian kepada masyarakat yang dilaksanakan di RT 07 ini adalah meningkatkan kemampuan seni pahat dan ukir masyrakat sehingga produk seni pahat dan ukir mereka dapat muncul kembali dengan kualitas yang bagus dan dikenal dandiminati masyarakat luas yang pada akhirnya timbul wirausaha baru seni pahat dan ukir.

Capaian yang diharapkan dalam pelaksanaan program ini adalah meningkatnya keterampilan dankualitas produk seni pahat dan ukir, meningkatnya penjualan dan pemesanan produk karena lebih bervariasi, meningkatnya pengetahuan masyarakat tentang adanya daerah penghasil seni kerajinan kayu yang bernuansa budaya lokal dengan model pemasaran memakai media on-line.

\section{METODE PELAKSANAAN}

Metode pelaksanaan dari pengabdian kepada masyarakat ini menggunakan model pelatihan partisipatif dengan cara melakukan pendampingan pembuatan produk mulai dari pemilihan dan pembuatan desain yang diminati masyarakat serta bernuansa budaya lokal, pelatihan pembuatan produk, pemahaman perlunya pemakaian insektisida alami untuk pengawetan bahan baku kayu sebelum diwarnai karena kualitas kayu yang beragam, pembuatan insektisida alami dari akar tuba, pembuatan dan pengelolaan media pemasaran on-line, serta pendampingan manajemen administrasi keuangan.

Langkah- langkah solusi yang telah disepakati bersama antara kelompok seni pahat dan ukir, ketua RW 02 dan TIM PKM Penguatan Kreatifitas Seni Pahat Kayu Berbasis Pengawet Alami adalah sebagai berikut:

1. Melakukan sosialisasi dengan masyarakat RT 07 dan beberapa masyarakat RW 02 yang difasilitasi oleh bapak RW 02 tentang adanya program pendampingan peningkatan seni pahat dan ukir dengan pendanaan dari DRPMDIKTI

2. Melakukan penambahan peralatan pahat dan ukir beserta peralatan penunjang lainnya untuk menghaluskan pahatan

3. Pelatihan pembuatan desain pahat dan ukir yang bernuansa budaya lokal serta yang bermanfaat bagi masyarakat umum

4. Pendampingan pembuatan produk

5. Pendampingan pewarnaan produk

6. Pendampingan pembuatan pengawet kayu alami

7. Pemdampingan pembuatan media pemasaran on-line

8. Pendampingan pembuatan sistem informasi keuangan sederhana.

9. Pendampingan pengawasan kualitas produk.

\section{Partisipasi Mitra dalam Pelaksanaan Program}

Kelompok seni pahat dan ukir dan RW02 kelurahan bakalan Krajan berpartisipasi dalam pelaksanaan program abdimas sebagai berikut:

1. Menyediakan tempat untuk pelaksanaan pelatihan 
2. Menyediakan bahan baku kayu untuk pelatihan

3. Menyediakan tenaga pembantu untuk pengelolaan media pemasaran on-line

4. Bersedia dilatih dan melanjutkan usaha seni pahat dan ukir

5. Bersedia menjaga dan merawat peralatan seni pahat dan ukir

\section{HASIL DAN PEMBAHASAN}

Sosialisasi program dihadiri oleh 9 (Sembilan) orang yang terdiri dari Bapak Ikhwanto selaku Ketua RW 02 Bakalankrajan, Pembina masyarakat 2 (dua)orang, UKM 2 (dua) orang, TIM PKM 3 (tiga) orang serta pembantu pelaksana 2 (dua) orang yang juga berfungsi sebagai pelatih. Sosialisasi program bertujuan agar masyarakat mengetahui adanya kegiatan pendampingan peningkatan keahlian seni pahat dan ukir serta pelaksananya. Pada kesempatan ini juga diadakan diskusi penentuan jadwal pelatihan dan tempat pelatihannya. Hasil diskusi tersebut memutuskan sosialisasi dan pelatihan diadakan di Balai RW 02 Bakalankrajan, sedangkan kelanjutan pengerjaannya dilakukan dirumah karena saat pagi hari sampai sore hari warga bekerja sebagai pekerja bangunan.

Pendampingan pengembangan materi juga dilaksanakan di balai RW. Materi yang diberikan meliputi materi pengembangan dari seni pahat dan ukir, materi pembuatan pengawet alami, buku buku penunjang yang berupa contoh - contoh desain yang beredar dimasyarakat beserta cara pembuatannya. Pada pertemuan ini juga dijelaskan pentingnya kombinasi warna, inovasi dan kreatifitas produk yang bermanfaat bagi masyarakat bernilai jual tinggi. Hasil pelatihan dipamerkan pada tanggal 1 April 2018 pada acara peresmian kantor RW 02 Kelurahan Bakalankrajan, meski produk yang dihasilkan masih kurang bagus meski sudah diminati oleh masyarakat. Pelatihan dilaksanakan terus sampai mendapatkan hasil yang bagus baik kualitas pahat dan ukir maupun komposisi pewarnaan. Pada proses pelatihan ini dihasilkan 4 (empat) produk kepala naga, satu keris ukiran dari kayu dan satu cermin ukiran kayu.

Hasil tersebut sudah dijual dan dipesan masyarakat, seni pahat kepala naga yang belum diwarnai laku seharga $\mathrm{Rp} 600.000,00$ sedangkan yang sudah diwarnai laku seharga Rp 900.000,00 per biji. Untuk penambahan hiasan pada kepala naga dijual dengan harga Rp 300.000,00. Sedangkan untuk cermin dan keris ukiran masih dalam pengerjaan dan harganya belum ditentukan.

\section{Produk sebelum pendampingan} pelatihan
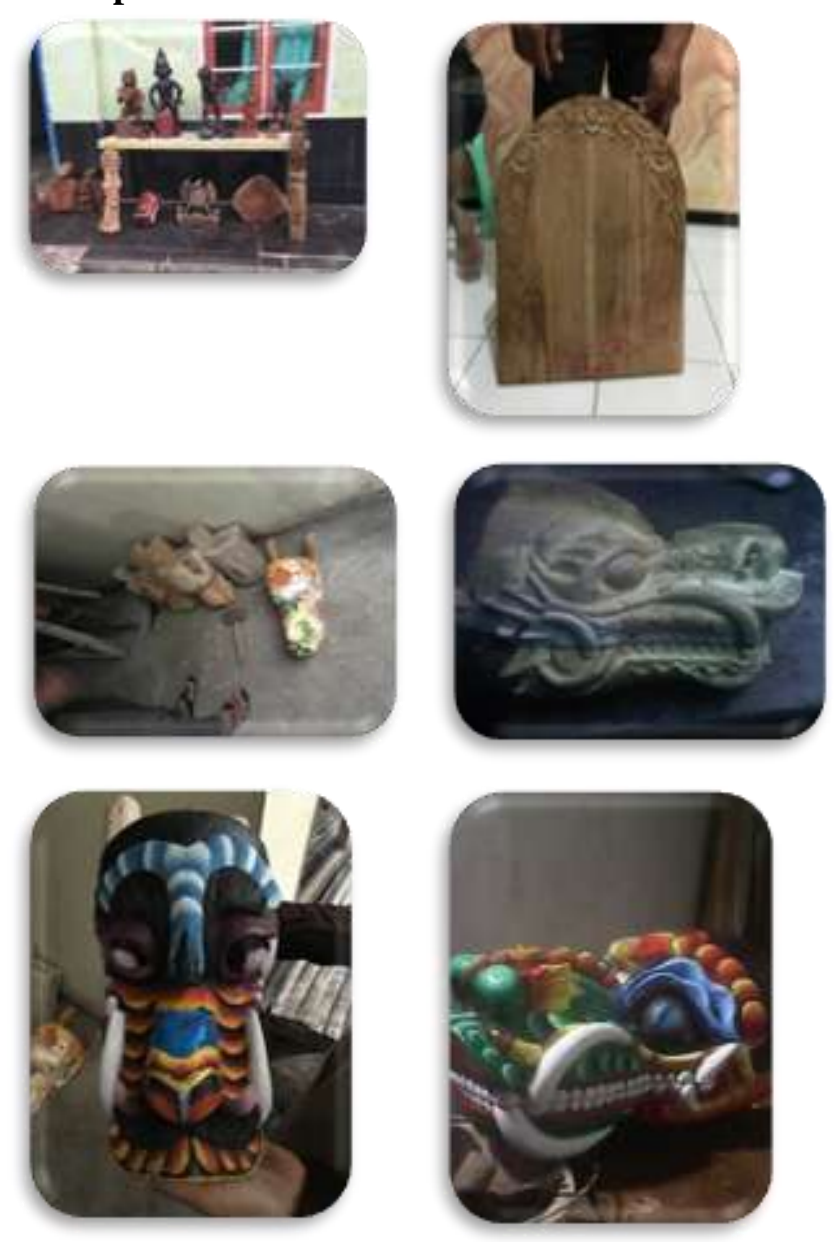

Gambar 2. Produk Seni ukir/pahat sebelum dan sesudah dilakukan pelatihan

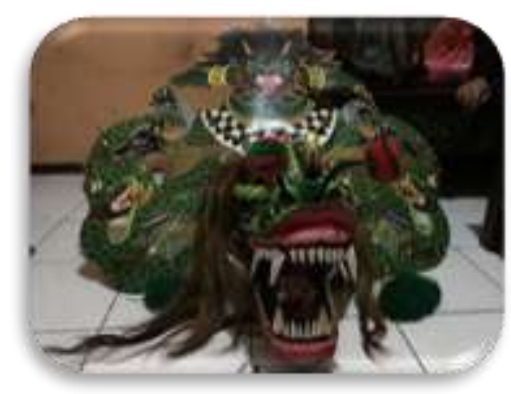

Gambar 3. Produk kepala naga dengan hiasan 
Hasil dari pembuatan media pemasaran on-line dapat mempromosikan hasil seni pahat dan ukir dan masyarakat umum menjadi tahu jika di Bakalankrajan ada UKM seni pahat dan ukir yang mencerminkan budaya lokal, hal ini dapat diketahui dari laporan umpan balik di media on-line tersebut.

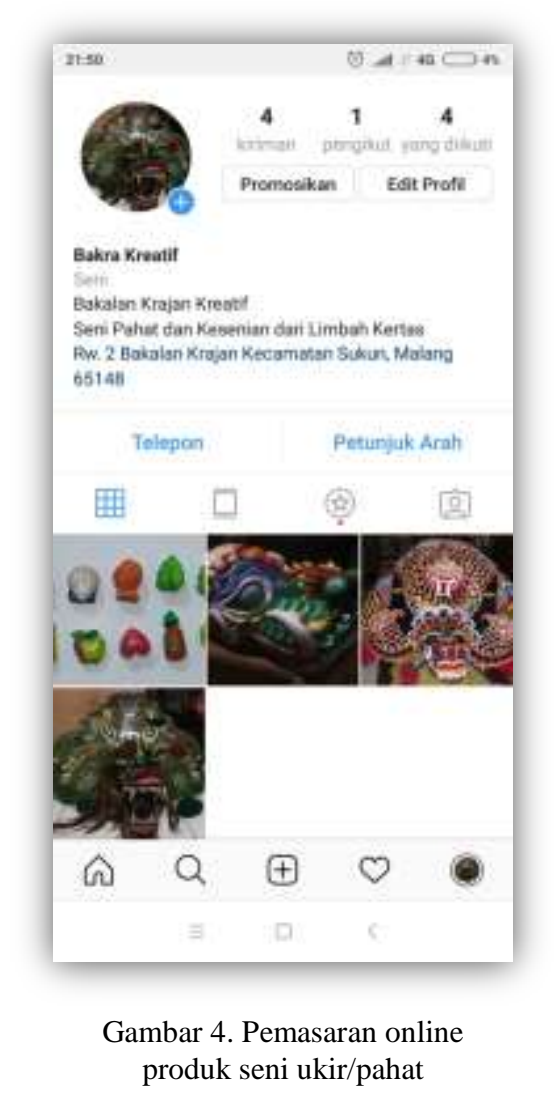

Pelatihan ini memerlukan kedisiplinan, kreativitas, motivasi yang cukup tinggi agar dapat meningkat produksinya sehingga dapat meningkatkan kesejahteraan masyarakat. Oleh sebab itu diperlukan pengontrolan dari Pembina masyarakat khususnya bapak ketua RW 02 agar keberlangsungan dapat terus berjalan.

\section{KESIMPULAN}

Pendampingan kepada masyarakat RT 07 RW 02 Bakalankrajan berhasil meningkatkan kemampuan masyarakat yang didampingi dalam hal peningkatan kualitas seni pahat dan ukir, kombinasi warna, kreativitas produk, pengawetan produk serta pemasaran memakai media on-line. Hal ini dapat diketahui dari kualitas produk yang laku dan ada masyarakat yang pesan serta ada masyarakat yang meminta tolong untuk memperbaiki produk yang sudah usang menjadi produk baru.

\section{DAFTAR PUSTAKA}

Data RW 02 Kelurahan Bakalan Krajan tahun 2014 http://kelbakalankrajan.malangkota.go.id/profil/petawilayah

https://m.tempo.co/read/news/2013/04/18/05847435 0/warga-temukan-candi-dan-permukiman-kunodi-malang

http://kelbakalankrajan.malangkota.go.id/2014/08/06 /peneliti-temukan-artefak-desa-kuni-di-malang

Jayadipraja, E. A., Iskak, H., Arsin, A. A., 2015. Uji Efektivitas Ekstrak Akar Tuba (Derris elliptica) Terhadap Mortalitas Larva Anopheles sp. Medicus Veterinus Indonesia, Vol. 4 (2) 2015. (ojs.unud.ac.id).

Safitri, R., Erniwati, Hapid A., 2014. Efektivitas Bahan Pengawet Alami Dari Tanaman Tembelekan (Lantana camara L.) Pada Beberapa Jenis Kayu Terhadap Serangan Rayap Tanah (Loptotermes sp.). Jurnal Warta Rimba Vol. 2, Nomor 2, Desember 2014. ISSN: 2406 -8373, Hal. $141-148$. 